\title{
Os Primeiros Processos Criativos de Bob Wilson e suas Relações com uma Infância Livre
}

\author{
Lucas Pinheiro \\ Universidade Estadual de Campinas - UNICAMP, Campinas/SP, Brasil \\ E-mail: lucasalpinheiro@gmail.com
}

Resumo

O presente ensaio busca refletir como os trabalhos iniciais de Bob Wilson relacionam-se com a ideia de uma infância livre e criadora - contrapondo-se àquela que é cerceada, guiada, induzida ou silenciada pela figura de um adulto, como pontua Hannah Arendt (2003). Para tanto, buscou-se uma intersecção de algumas reflexões sobre a infância presentes em Marina Machado (2010a; 2010b; 2013; 2014; 2016), Manuel Sarmento (2002; 2008), Hannah Arendt (2003) e Jorge Larossa (1988), dentre outros, com as primeiras experiências teatrais de Wilson, no início de 1970.

\section{Palavras-chave}

Bob Wilson. Teatro. Infância. Criança. Poéticas de Criação.
The present essay seeks to reflect how Bob Wilson's early works relate to the idea of a free and creative childhood - in contrast to that which is surrounded, guided, induced or silenced by the figure of an adult, as points out Hannah Arendt (2003). To this end, we sought to intersect some reflections on childhood present in Marina Machado (2010a; 2010b; 2013; 2014; 2016), Manuel Sarmento (2002; 2008), Hannah Arendt (2003) and Jorge Larossa (1988), among others, with Wilson's first theatrical experiences, in the early 1970 s.

Keywords

Bob Wilson. Theater. Childhood. Infant. Poetic Creation. 


\section{Introdução}

Com mais de cinco décadas de trabalho, o encenador estadunidense Bob Wilson (1941 - ) é um dos principais artistas da cena teatral contemporânea. Embora ele não tenha sido poupado do destino comum de muitos de seus pares, já que seus últimos trabalhos retomaram aqueles recursos teatrais que, quando eram novos, fizeram com que se revisse o espaço teatral de uma época (PINHEIRO, 2017), poucos artistas teatrais modificaram tanto este campo e influenciaram tanto as possibilidades de se pensá-lo como Wilson.

Salvo poucas exceções, são escassos os trabalhos produzidos no Brasil (GALIZIA, 2004; TONEZZI, 2011; PINHEIRO, 2017), ou para cá traduzidos (LEHMANN, 2007), que se debruçam a analisar e tentar compreender as maneiras com que a cena artística wilsoniana ganhou vida: quais foram os disparadores e questionamentos que estruturaram, e continuam a estruturar, seus trabalhos. Dentre muitos, um dos reflexos disso pode ser notado no desconhecimento acerca da importância das crianças no que tange o início dos seus processos criativos.

Este ensaio, através de uma breve reflexão sobre a ideia de infância, nos preceitos de Marina Machado (2010a; 2010b; 2013; 2014; 2016), Manuel Sarmento (2002; 2008), Hannah Arendt (2003) e Jorge Larossa (1988), busca disseminar as maneiras com que Bob Wilson, tendo como auxílio a perspectiva e criatividade de algumas crianças, começou a refletir e estruturar sua cena teatral, no início de 1970.

\section{Sobre a infância}

O imaginário infantil é concebido como a expressão de um déficit - as crianças imaginam o mundo porque carecem de um pensamento objetivo ou porque estão imperfeitamente formados seus laços racionais com a realidade. Esta ideia de déficit é inerente à negatividade na definição de criança. (SARMENTO, 2002, p. 2)
Para cada noção de infância e criança há um modo de ser, estar e agir da comunidade adulta. Assim, "assistimos por décadas à supremacia de um modo adulto em pensar a infância" (MACHADO, 2014, p. 4), ignorando, na maioria esmagadora das vezes, a própria criança nessa equação. Como bem pontuou Hannah Arendt (2003), no texto $A$ crise da Educação, presente no livro Entre o passado e o futuro, se nos colocarmos no ponto de vista da criança, é possível perceber como são praticamente nulas as hipóteses que ela tem de fazer qualquer coisa que parta de sua iniciativa própria - sendo constantemente cerceada, guiada, induzida ou silenciada pela figura de um adulto.

No Brasil, as maneiras adultas de ver, educar e entender a infância foram fortemente influenciadas por Jean Piaget (1896-1989) e Lev Vygotsky (1896-1934), principalmente no que concerne à Educação. Sobre estas influências, em um artigo, intitulado Teatro e infância, possíveis mundos de vida (e morte), Marina Machado traz a seguinte reflexão:

O brilhantismo de Piaget foi embaçado por
sua abordagem científica, não-histórica e
socialmente fora de contexto. O que quer
que observasse como expressão genética
da conduta infantil no princípio do século
XX, ele generalizava para todas as culturas
e eras históricas - um erro que causou sé-
rias consequências para aqueles que se in-
teressavam por crianças. Considerando os
estágios do desenvolvimento biológico da
criança como fixos e imutáveis, professores,
psicólogos, pais, assistentes sociais e a co-
munidade em geral viam e julgavam a criança
através de uma classificação de desenvolvi-
mento fictícia. As crianças que não ‘atingiam
o padrão' seriam relegadas ao grupo de bai-
xa expectativa e desempenho. As que 'al-
cançavam a meta' descobririam que seu pri-
vilégio econômico e racial seria confundido
com capacidade. (MACHADO, 2014, p. 4).

Nesse mesmo artigo, Machado (2014) afirma que o problema não está em Piaget (1978) ou Vygotsky (2003), mas no modo dogmático com que os pontos de vista e as inferências desses autores foram e são adotados: como se fossem 
verdades absolutas. Com uma linha de pensamento muito semelhante ao de Machado, Jorge Larrosa, que também problematiza a compreensão de uma educação que, via instituições, saberes e práticas, cerceia e classifica a infância, afirma:

A infância é algo que nossos saberes, nossas práticas e nossas instituições já capturaram: algo que podemos explicar e nomear, algo sobre o qual podemos intervir, algo que podemos acolher [...]. Nós sabemos o que são as crianças, ou pretendemos saber, e procuramos falar uma língua que as crianças possam entender, quando tratamos com elas nos lugares que organizamos para albergá-las. [...] Não obstante e ao mesmo tempo, a infância é o outro: aquilo que, sempre muito além do que qualquer tentativa de captura, inquieta a segurança de nossos saberes, questiona o poder de nossas práticas e abre um vazio no qual se abisma o edifício bem construído de nossas instituições de acolhimento. Pensar a infância como algo outro é, justamente, pensar essa inquietude, esse questionamento e esse vazio. É insistir mais uma vez: as crianças, esses seres estranhos dos quais nada se sabe, esses seres selvagens que não entendem nossa língua. (LARROSA, 1998, p. 67).

Ocorre que na busca por tentar compreender "esses seres selvagens que não entendem nossa língua” (LARROSSA, 1998, p. 67), as crianças, ao invés de levarmos em conta as suas vozes, escutamos apenas o que os adultos têm a dizer sobre elas. Pensamos e agimos dentro de uma lógica centrada nos construtos culturais acerca da infância, dos saberes adultocentricos, que se desenvolveram ao longo dos últimos quatro séculos sobre ela.

Consequentemente, caímos em estereótipos e maneirismos ${ }^{1}$, assumindo, em geral, um modus operandi muito específico em relação à infância e aos sujeitos que a ela estão arraigados: induzimos as crianças a dizer determinadas coisas; a abraçar pessoas que elas não querem e a vestir roupas das quais elas não se sentem confortáveis, por exemplo; insistimos

1 Falo aqui acerca da minha experiência de mais de uma década trabalhando com crianças, especialmente focado na faixa etária de quatro a dez anos. em falar com elas como se fossem menos que os adultos, de forma extremamente infantilizada²; insistimos em repetir, às vezes mais de uma vez, frases que acabamos de dizer e, ao fazê-lo, suprimimos palavras para que elas possam completar as frases que exaustivamente foram reiteradas por nós. Ou seja, a criatividade das crianças, as suas habilidades de pensar por si próprias e de tomar determinadas decisões, são constantemente subjugadas por nós (adultos). A elas, cabe apenas acatar, agir e completar os espaços e ações que o adulto já começara a preencher.

Essas maneiras adultas de agir não levam em conta o fato de que a criança é um Outro; um Outro ser humano; uma Outra pessoa com identidade, vontades e desejos próprios; um Outro que compartilha o mesmo mundo do adulto; não leva em conta que ela vê, percebe e vive o mundo, em sua própria perspectiva, mas não ensimesmada ou reclusa em seu próprio mundo, um mundo da criança. É uma visão de que a criança, enquanto criança for, para sempre será um infante - alguém que, em razão da pouca idade, não é capaz de falar.

É por isso que se faz necessário respeitar a infância da criança com que lidamos, compreendendo-a como alguém diferente de nós e que pode nos dizer, à sua própria maneira, o que realmente é e do que realmente precisa. Para isso, entretanto, precisamos ouvi-la. Precisamos entender, como pontuam Larossa (1998) e Machado (2010a, 2010b, 2013, 2014, 2016), que todo ser humano, independentemente de sua faixa etária, é um ser único, que carre-

2 Esta maneira infantilizada de se falar com as crianças chama-se "manhês". De acordo com Catão (2009), o "manhês" pode ser descrito como um modo especial de fala materna dirigida ao bebê, tendo características peculiares em relação à sintaxe (frases curtas e repetições), ao léxico (simplificação morfológica e multifuncionalidade de palavras) e à prosódia (tom de voz mais agudo, velocidade lenta e alongamento de vogais). Essas características fazem com que o bebê se interesse e procure com o olhar a pessoa que se dirige a ele, pois "a fala materna, que implica desejo, convoca o bebê a buscar ativamente o olhar do outro. Em contrapartida, o bebê se esquiva de procurar o olhar e de participar de um diálogo, mesmo sem palavras, com uma pessoa que não demonstre o desejo ao falar (manhês)" (FLORES, 2011, p. 144). 
ga consigo todas as possibilidades inerentes à vida.

O professor e pesquisador Manuel Jacinto Sarmento (2008) argumenta que a infância não é a idade da não fala, uma vez que todas as crianças, desde bebês, têm múltiplas linguagens pelas quais se expressam. De acordo com ele, a "infância não vive a idade da não infância: está aí, presente nas múltiplas dimensões que a vida das crianças (na sua heterogeneidade) continuamente preenche" (SARMENTO, 2008).

Não se trata, portanto, de reduzirmos a infância a algo que, de antemão, já sabemos o que é, o que quer ou do que necessita. Não se trata, tampouco, de que vejamos a infância como aquilo que temos de integrar em nosso mundo, pois ela já está no mundo. O que podemos fazer, como pontuam os autores supracitados, seria pensar e entender as crianças como existência de pluralidades, de experiências, de novidades e continuidades. Quer dizer, o "enigma da infância" (LAROSSA, 1998, p. 196) tangencia-se no ato de ver e considerar as crianças como indivíduos que alcançam o seu verdadeiro eu no instante em que "aparece como alguém singular e irrepetível, como uma pura diferença irredutível a qualquer conceito, como uma pura presença irredutível a qualquer causa, condição ou fundamento" (LAROSSA, 1998, p. 196). Nesse sentido, quando se reconhece a autonomia das crianças sobre elas próprias, suas vontades e anseios, é que as respeitamos enquanto indivíduos.

Corroborando com estas ideias, e sendo salutar a elas, podemos encontrar a seguinte constatação de Reinaldo Damazio no livro O que é criança:

Toda nossa prática vai no sentido de transformar a criança no adulto e, pior, no adulto que já somos, que idealizamos e que desejamos; ajustando-a aos nossos planos e anseios, sob nossa ótica e aspirações, segundo nossos próprios objetivos [...] toda criança, o que significa todo novo indivíduo (e toda uma nova geração de indivíduos), traz em potencial uma rica gama de possibilidades renovadoras, ainda que a sociedade opere dominantemente com padrões de repetição. (DAMAZIO, 1991, p. 24-6).
Considerar, então, a criança como um ser em desenvolvimento, que já atua no mundo e, portanto, interfere nele, implica o seu reconhecimento como uma outra pessoa, como um ser em constante construção e que irá se reconstruir por toda a vida. Desconsiderar a criança como um ser que já tem percepções próprias implica em desautorizar, automaticamente, a diversidade da sua existência; considerando-a como um ser incompleto, que tornar-se-á completa à medida em que os anos forem passando.

O nosso equívoco, talvez, esteja em ver a criança como uma miniatura do adulto, alguém que está à espera para crescer, e não como uma pessoa ávida de sensações, conhecimentos e perspectivas que Ihe são próprias. Cair no modus operandi adulto de interagir com as crianças é ignorar a possibilidade de apreender o mundo mediante as suas concepções, estabelecendo com elas diálogos que se instauram para além dos verbos e das construções frasais, mas por meio, também, da interação.

É preciso, portanto, pensar as crianças a partir delas próprias, enxergando-as como autoras de sua socialização, como criadoras e significadoras das suas próprias existências. Para tanto, é necessário vê-las como seres-no-mundo que, embora permeadas de limitações, dada pela imaturidade de seus corpos e pelas molduras culturais em que estão inseridas, já são pessoas. E, sendo assim, aptas a

[...] dizer algo sobre tudo isso: dizer algo em seu corpo, gestualidade, gritos, choro, expressões de alegria e consternação, espanto e submissão. Esses dizeres em ação, essas atuações no corpo, mostram-se repletas de teatralidade: pequenas, médias e grandes performances, ações de suas vidas cotidianas que encarnam formas culturais no ser total da criança. (MACHADO, 2010a, p. 126, grifo nosso).

Se assim o adulto a considerar, cabe a ele ser um receptáculo de suas ações, alguém que positive suas capacidades imaginativas e criativas (MACHADO, 2010b), e não como "alguém que reduz a infância a algo que de antemão já sabe o que é, quer ou necessita" (LARROSA, 1998, p. 73). A criança, 
neste sentido, é uma performer da sua vida cotidiana (MACHADO, 2010a), repleta de teatralidades. E o encenador Bob Wilson parece ter percebido e respeitado isso desde o início da sua carreira, uma vez que ele foi o primeiro encenador do ocidente a colaborar criativamente, sem paternalismo, com crianças com variados tipos de deficiência (PINHEIRO, 2017).

\section{As relações de Bob Wilson com a infância}

Para que se possa compreender de quais formas as experiências teatrais de Bob Wilson relacionam-se às ideias que até aqui apresentamos, é necessária uma breve descrição de alguns eventos que marcam sua biografia, pois estes estão intrinsecamente amalgamados aos seus procedimentos estéticos inicias que, por sua vez, influenciaram sua maneira de agir e entender a infância e os sujeitos a ela arrolados.

Nascido em 1941, em Waco, uma pequena cidade conservadora e segregacionista dos Estados Unidos, quando pequeno, tinha a língua presa, era gago e disléxico, o que dificultou sua sociabilização; as dificuldades em falar e ser compreendido, somadas à insegurança e à vergonha, o fizeram voltar-se para si mesmo, para seus desenhos e pinturas.

Ao completar dezessete anos ele conheceu Byrd Hoffman, uma professora de ballet aposentada de sua cidade natal - que estava com pouco mais de setenta anos e que é considerada a primeira artista com a qual ele teve contato. Foi esta senhora, professora de dança, que através de exercícios de relaxamento físico e de extensão temporal para a realização de determinadas ações (como o ato da fala, por exemplo), que fez com que Wilson superasse suas dificuldades vocais, ao mesmo tempo que passasse a perceber o mundo de uma outra forma. Em suas próprias palavras:

A maior parte era medo de não ser capaz de falar. Quando eu tinha dezessete anos meus pais já haviam me levado a uma infinidade de pessoas, profissionais, para me ajudar com a fala e eu ainda não havia aprendido a falar - então eu conheci uma mulher que foi uma dançarina. [...] ela entendia o corpo de uma forma extremamente marcante, ela disse "oh, você pode aprender a falar, eu sei que pode", e em questão de três meses trabalhando com ela eu consegui, de alguma forma relaxando e levando o meu tempo, eu finalmente aprendi a falar. [...] Eu entrei em meu corpo e fui capaz de liberar a tensão. [...] Ela notou que eu era muito, muito tenso desde os ombros até os quadris. Então, ela me falou sobre a energia do meu corpo, sobre relaxar, como deixar a energia fluir através dele e, então, eu não estava mais bloqueado. (BRECHT, 1978, p. 14).

Em 1959 Wilson inicia seus estudos na área de administração, na Universidade do Texas, abandonando-a prestes a se formar. Todavia, foi dentro desta instituição que ele começou a desenvolver trabalhos de natureza teatral com inúmeras crianças. E, ao invés de mandá-las executarem determinadas ações ou de chegar com uma ideia pronta, recheada de "didatismos autoritários"3 (PUPO, 1991), Wilson apenas as escutou, percebendo o que queriam fazer, e auxiliando-as nesse processo:

Eu sempre fiz trabalhos teatrais com crianças e este sempre foi o trabalho delas. [...] elas escreviam as peças que encenávamos e eram as próprias performers das ações. [...] Eu comecei quando eu me formei no ensino médio. Havia uma centena de crianças envolvidas com o programa de teatro da cidade - e então eu fui para a Universidade do Texas por um tempo e comecei a trabaIhar com crianças lá. Nós as colocávamos para montar as peças e as apresentávamos em todos os lugares, em construções, em igrejas, em garagens, terrenos baldios [...] Nós quase nunca pegávamos textos prontos, com exceção de "Peter Pan" e "Alice no país das maravilhas", mas que elas mesmas adaptaram. [...] Eu as ajudava, mas era basicamente o trabalho delas. $\mathrm{Na}$ verdade, o que eu posso chamar como sendo de minha autoria era o fato de colocá-las para trabaIhar em conjunto. [...] Eram elas próprias que dirigiam, faziam os cenários e todo o resto. (BRECHT, 1978, p. 15, grifos nossos).

3 Fato de os espetáculos teatrais ligados à infância focarem em conteúdos e temas moralizantes. 
Todavia, muitas dessas experiências não foram bem recebidas pelos pais da conservadora Waco, da década de 1960. Em uma dessas apresentações, por exemplo, criada e realizada por meninos de dez anos de idade, após apenas dez minutos, uma das mães subiu no palco e retirou de lá o seu filho, falando: "Eu gostaria que todas subissem e tirassem os seus filhos daqui, porque isso é doentio" (ABSOLUTE WILSON, 2006, 10 seg.)

Como os registros dessa apresentação se limitam a uma pequena entrevista de Wilson, não há como sabermos o que de fato aconteceu no palco para que aquela mãe reagisse da maneira com que o fez. Podemos supor que a atitude dessa mãe resvale na "intelectualização da experiência infantil" (MACHADO, 2010b), a saber: o ato dos adultos de desfazerem todo e qualquer equívoco infantil que parta de uma vida rica de fantasia e imaginação, típicas da infância. Quaisquer que sejam os reais motivos que fizeram com que a referida mãe interrompesse a apresentação, isso fez com que Wilson cessasse, momentaneamente, suas experiências cênicas.

Esse hiato durou cerca de cinco anos.

Em 1966, graduando-se em arquitetura pelo Pratt Institute (Nova York), Wilson sofreu um colapso nervoso, que o levou a uma tentativa de suicídio. Momento decisivo, não só na sua vida, como em sua carreira, pois foi o momento em que ele percebeu que deveria voltar a dedicar-se à arte teatral.

E assim o fez.

A convite de sua antiga professora, Byrd Hoffman, ele retorna à sua cidade natal para desenvolver experiências artísticas com crianças com danos cerebrais. Este trabalho, próximo ao terapêutico, não tinha como foco a composição de um material cênico a ser apresentado, mas a compreensão e o desenvolvimento das potencialidades individuais de cada uma dessas crianças, em suas próprias condições, através de processo artísticos. Semelhante ao que ocorreu com o próprio Wilson ao conhecer Hoffman, sete anos antes.

O próprio afirma que, quando iniciou este trabaIho, algo mudou; que por intermédio dessas experiên- cias ele começou a enxergar e a entender o mundo de uma outra forma, tendo como referência o potencial destas crianças (BRECHT, 1978). Compreendê-las, portanto, enquanto agentes ativas em seus processos de autoconhecimento e desenvolvimento foram um dos motivos que levaram Wilson a ter um trato particular e, em alguns aspectos, inovador, não só com relação à composição cênica como com aqueles que nela estão envolvidas (PINHEIRO, 2017).

A seguinte entrevista de Wilson a Arthur Holmberg enfatiza o que estamos dizendo até aqui: que, em nenhum momento, o encenador tentou impor padrões de comportamento ou cerceou a liberdade criativa das crianças e/ou indivíduos com que colaborou:

Eu trabalhei com crianças hiperativas e com danos cerebrais. Depois eu comecei a trabalhar com pessoas presas a "máquinas de respiração", muitas das quais eram catatônicas. Fui contratado para fazer as pessoas falarem. [...] Trabalhei lá por dois anos e no final eu cheguei à conclusão que não era necessário encorajar aquelas pessoas a falarem. Eu trabalhei com crianças na pré-escola em Harlem, com pessoas idosas em New Jersey e com pacientes de instituições mentais. Em todas as aulas eu não estava ali para ensinar nada, mas para ouvir e descobrir o que eles estavam interessados e ajudá-los a fazer o que gostariam de fazer. (HOLMBERG, 1996. p. 3).

Foram essas primeiras experiências teatrais que estruturam o alicerce das concepções artísticas de Wilson, transformando-se tanto na sua base estética como em norteador às suas investigações futuras. Foram elas que, de uma certa maneira, "abriram as portas" para que durante a década de 1970 , e dando início a sua carreira profissional, o encenador colaborasse proficuamente com Raymond Andrews e Christopher Knowles - ambos com doze anos; o primeiro surdo e o segundo diagnosticado como autista (PINHEIRO, 2017). 
Essas colaborações, que resultaram em encenações internacionalmente reconhecidas ${ }^{4}$, também são capazes de desvelar as relações de Wilson com a ideia de uma infância livre e criadora - esmiuçada anteriormente neste ensaio.

Com relação a Raymond Andrews, por exemplo, que foi adotado por Wilson ${ }^{5}$, é visível o quão o encenador deu espaço para que o garoto pudesse existir e agir, à sua própria maneira - o que auferiu mudanças significativas no que tange à concepção visual de suas obras. Segundo Andrew DeGroat ${ }^{6}$, "Raymond era incapaz de ouvir e falar, o que deu a Bob a possibilidade e o dever de usar gestos e efetuar mudanças na forma com a qual apresentávamos as coisas para que, assim, Raymond pudesse participar" (ABSOLUTE WILSON, 2006, $39 \mathrm{~min}$ ).

Desse modo, durante os workshops de criação dos espetáculos King of Spain (1969), Deafman Glance (1970) e The Life and Time of Joseph Stalin (1973), tanto Wilson quanto os membros da Byrd Hoffman School of Byrds ${ }^{7}$ tentavam aprender e imitar a linguagem corporal, os gestos, os sons, a maneira de mover e agir de Andrews - essas partituras corporais, recém adquiridas, foram adicionadas a diversas cenas desses espetáculos.

4 Dentre tantas, destacamos: King of Spain (1969), Deafman Glance (1970), The Life and Times of Joseph Stalin (1973), A Letter for Queen Victoria (1974) e Einstein on the Beach (1976) - esta última também em parceria com o musicista Philip Glass.

5 Nenhuma das pessoas que estava ao redor de Raymond Andrews, durante seu crescimento, tinha conhecimento de sua surdez. Por conta disso ele era tratado como um "ineducável" e era constantemente rechaçado. O menino, com doze anos de idade, iria ser transferido para uma espécie de "casa de delinquentes", mas Wilson interveio e o adotou.

6 DeGroat é um coreógrafo estadunidense. Durante a década de 1970 colaborou proficuamente com Wilson em inúmeras peças, dentre elas "Einstein on The Beach" (1976).

7 Grupo de performers amadores, alguns dos componentes Wilson, literalmente, encontrou pelas ruas e durante toda a década de 1970 fizeram parte das produções wilsonianas. Posteriormente, o grupo deixou de existir e Wilson fundou a The Byrd Hoffman Watermill Foundation.
De uma certa maneira, pode-se dizer que Wilson adotou a criança para educá-la, mas, em oposição, quem foi educado por Andrews foi o próprio encenador - e todos os outros performers dos espetáculos. Isso só foi possível porque o adulto da relação não menosprezou a criança, não a viu como alguém menos, mas a entendeu como um Outro - buscando entender as suas ações como gestos performativos de sua própria existência.

Com Christopher Knowles ocorreu um processo semelhante. Wilson não se tornou pai do garoto, mas adotou-o artisticamente, dando espaço dentro do espetáculo The Life and Times of Joseph Stalin ${ }^{8}$ (1973) para que o menino fizesse o que ele fazia de melhor: expor os seus autísticos pensamentos na forma de poesia sonora. Posteriormente, as poesias produzidas pelo garoto se transformaram na dramaturgia sonoro-verbal de diversos espetáculos wilsonianos.

Juntos, entre 1973 e 1980, eles criaram pelo menos um projeto por ano, a maioria deles performances intituladas Dialogs/Networks: encontros performáticos que usualmente combinavam falas produzidas ao vivo com outras pré-gravadas por Knowles. Além dessas performances, a parceria entre ambos resultou na criação de diversos espetáculos, entre eles: A Letter For Queen Victoria (1974), The \$ Value of Man (1975) e Einstein on the Beach (1976).

Outro momento capaz de nos mostrar a sensibilidade de Wilson com relação à infância, e o quão ele estava interessado na criança como agente de sua existência, é uma história narrada por Ed Knowles, pai de Christopher Knowles, sobre as visitas do encenador ao centro psiquiátrico Heck School:

Havia, talvez, oito ou dez crianças com severos problemas, problemas neurológicos, tanto física como mentalmente... E havia um pequeno menino com no máximo um metro de comprimento, com cerca de seis anos, que tinha os braços tão longos quanto

8 Esse espetáculo foi apresentado no Brasil em 1974, entretanto, para evitar problema com a censura militar da época, aqui ele se chamou, sob imposição, The Life and Times of Dave Clark - um nome que retirava qualquer conotação política que houvesse dentro da peça. 
um polegar. Ele só ficava deitado lá, choramingando, enquanto uma mulher ficava sentada ao seu lado afagando suas costas e tentando consolá-lo.... À direita deles havia um daqueles órgãos elétricos - havia dois, na verdade - então Bob foi até a criança e o tocou ... com as costas das mãos, com a parte de trás dos dedos. E a criança parou de choramingar e com muito esforço levantou a cabeça para cima. Então Bob, com a criança ainda o seguindo com o olhar, foi até um desses órgãos e apenas colocou suas mãos sobre as teclas fazendo barulho. E ele apenas se manteve lá. A criança olhou para as próprias mãos e engatinhou até o órgão e tocou nas teclas, fazendo barulho. Aquela foi a primeira vez que a criança, durante todo o tempo que esteve na escola, havia feito algo voluntariamente. Então ele olhou para o Bob, meio que querendo dizer, "Veja, eu também posso fazer isso". E muito gentilmente Bob moveu suas mãos fazendo um som diferente; e a criança percebeu que ela também poderia fazer um som diferente. $O$ choramingar cessou. De repente, ele estava fazendo algo que era significativo. Ele havia aprendido algo diferente. [...] Foi uma questão de o Bob entender qual era o ritmo da criança e ser capaz de trabalhar com ela em tais ritmos. É claro que todos ficaram estarrecidos, pois em questão de cinco minutos ele havia conseguido fazer a criança agir, quando mais ninguém havia sido capaz de tal façanha. (SHYER, 1989, p. 74)

Após inúmeras visitas de Wilson ao centro psiquiátrico, os pais de Knowles - assim como a equipe médica - se convenceram de que o melhor para ele seria deixar a instituição e acompanhar o encenador em sua trajetória artística. Em decorrência disso, Knowles passou inúmeros meses no loft do encenador, na Spring Street, colaborando com ele e com os Byrds, aprimorando e potencializando suas habilidades sonoro-verbais. A parceria entre ambos, por intermédio da forma peculiar do jovem Knowles de lidar com os códigos linguísticos, alteraram as concepções wilsonianas acerca da estruturação de suas obras.

Estes exemplos, para além de brevemente elucidar as maneiras com que Bob Wilson iniciou sua trajetória artística, também são capazes de demonstrar não só sua habilidade em trabalhar com crianças, mas o seu respeito para com elas. Portanto, e tal qual Wilson se propôs a fazer, podemos buscar entender o espaço teatral como uma instância capaz de positivar a capacidade imaginativa e a singularidade das crianças. Um lugar onde suas vozes e suas ações possam ser vivenciadas sem que preocupações adultas (e negativizantes) tentem trazer as crianças à "realidade". Positivar essas qualidades, como pontuou Machado, é deixar com que aconteça todo e qualquer fluxo imaginativo, sem que haja "noções adultas pressupostas e, se necessário, com muito diálogo à posteriori - especialmente no caso de a criança ser tomada por sua própria capacidade imaginativa, expressando medo, pavores e receios" (MACHADO, 2010b, p. 289).

\section{Considerações finais}

Foram nestas relações cênicas com a infância, em caráter de colaboração artística, que Bob Wilson emergiu enquanto um dos grandes nomes da contemporaneidade. Foi do fato de ter enxergado potência artística nos modos de ser dessas crianças que fez com que ele pudesse se deixar influenciar pelas perspectivas delas. Não as menosprezando ou considerando-as como seres inferiores aos adultos, mas respeitando-as e deixando-as livres para criar e experimentar.

É devido principalmente as colaborações de Wilson com Raymond Andrews e Christopher Knowles que inferimos que o encenador, no início da sua carreira, entendia as crianças como autoras de suas próprias existências, como performers da sua vida cotidiana (MACHADO, 2010a), tendo a diversidade das suas existências respeitadas. Ele é apenas um exemplo de como isto é possível. Outros também o fizeram e ainda o fazem, como, por exemplo, o italiano Romeo Castelluci (CRUVINEL, 2014) ou a francesa Ariane Mnouchkine (CRUVINEL, 2014). Sabemos que não há dragões e que o chão da nossa sala não é feito de lava vulcânica, mas no espaço ficcional da teatralidade, isto é possível, é experienciado e vivido. Cabe a nós, ar- 
tistas da cena, nos atentarmos a isso quando formos trabalhar, experienciar e criar com as crianças.

Para além das noções piagetianas (1978) ou vygostkyanas (2003) de jogos simbólicos - já que esses autores o consideram como um fator determinante para o desenvolvimento infantil, o que intelectualiza a experiência - o teatro, se pautado nestes pressupostos, pode vir a ser um lugar que permita às crianças ser o que elas são, explorando e potencializando suas capacidades criativas; sem que haja a necessidade de roteiros prévios e/ou imutáveis, sem intervencionismos adultos excessivos, deixando de lado as teorias psicológicas e/ou pedagógicas sobre o que é a infância ou o brincar. Afinal, de acordo com Machado:

Menos intervencionismo adulto geraria crianças mais autônomas, protagonistas, performers de suas existências. Menos intervencionismo e mais co-pertença, cumplicidade e hospitalidade, é o esperado para uma relação adulto-criança onde adultos desejem sinceridade, que as crianças sejam bem-vindas ao mundo compartilhado, que usufruam dele e o transformem, a seu modo. (MACHADO, 2013, p. 258).

Podemos, então, pensar e utilizar o hibridismo entre realidade e ficção, inerente ao fazer teatral, para entender a infância por outras perspectivas: como um espaço onde as vozes das crianças possam ser ouvidas; onde suas existências e ações sejam significativas e falem per si; onde não seja necessário a interferência de um adulto que apenas Ihes veja como seres menores, que estão aguardando para um adulto se tornar. Um espaço seguro à criatividade, no qual a criança seja capaz de alcançar "o verdadeiro no próprio instante em que aparece como alguém singular e irrepetível" (LAROSSA, 1998, p. 196). Tornar-se alguém capaz de (re)ensinar para nós, adultos, o que é ser criança.

\section{Referências}

ABSOLUTE WILSON. Direção: Katharina Otto-Bernstein. Produção de Katharina Otto-Bernstein. Estados Unidos: Film Manufactures, 2006. 1 DVD. (105min).

ARENDT, Hannah. A crise na educação. In: Entre o passado e o futuro. São Paulo: Perspectiva, 2003, p. 493-513.

BRECHT, Stefan. The Theatre of Visions - Robert Wilson. Frankfurt: Suhrkamp Verlag Franfurt, 1978.

CATÃO, Inês. O bebê nasce pela boca: voz, sujeito e clínica do autismo. São Paulo: Instituto Langage, 2009.

CRUVINEL, Tiago de Brito. A criança em cena: análise da atuação e de processos criativos com crianças-atores. Curitiba: Editora CRV, 2014.

DAMAZIO, Reinaldo Luiz. O que é criança. São Paulo: Brasiliense, 1991.

FLORES, Marina. et. al. O manhês e suas implicações para a constituição do sujeito na linguagem. Distúrb. Comum., São Paulo, n. 23, p. 143-152, 2011.

GALIZIA, Luiz Roberto Brant de Carvalho. Os Processos criativos de Robert Wilson: trabalhos de arte total para o teatro americano contemporâneo. Tradução do autor e Carlos Eugenio Marcondes de Moura. São Paulo: Perspectiva, 2004.

HOLMBERG, Arthur. Directors in Perspective: The Theatre of ROBERT WILSON. Massachusetts: Cambridge University Press, 1996.

LARROSA, Jorge. Pedagogia profana: danças, piruetas e máscaras. Tradução Alfredo Veiga-Neto. Porto Alegre: Contrabando, 1998. 
LEHMANN, Hans-Thies. Teatro pós-dramático. Trad. Pedro Süssekind. São Paulo: Cosac \& Naify, 2007.

MACHADO, Marina Marcondes. A criança é performer. Educação e Realidade, n. 35, v.2, p. 115-137, 2010a.

O imaginário infantil como trabalho-em-processo. childhood \& philosophy, rio de janeiro, v.6, n. 12, p. 281-295, 2010 b.

Fenomenologia e Infância: o direito da criança a ser o que ela é. Revista de Educação Pública, [S.I.], v. 22, n. 49/1, p. 249-264, 2013.

Teatro e infância, possíveis mundos de vida (e morte). Revista Aspas (USP), n.2, v.4, p. 3-14, 2014.

Infância é corpo encarnado / uma perspectiva poético-existencial para o ser criança. childhood \& philosophy, Rio de Janeiro, v. 12, n. 24, p. 455-468, 2016.

PIAGET, Jean. Formação do símbolo na criança. Rio de Janeiro: Zahar, 1978.

PINHEIRO, Lucas de Almeida. Bob Wilson: por trás do olhar de um surdo e da voz-pensamento de um autista. 2017. 220 f. Dissertação (Mestrado em Artes da Cena). Programa de Pós-Graduação em Artes da Cena, Universidade Estadual de Campinas, Campinas, 2017.

PUPO, Maria Lúcia. No reino da desigualdade. São Paulo: Perspectiva, 1991.

SARMENTO, Manuel Jacinto. Imaginário e culturas da infância. Texto produzido no âmbito das atividades do Projeto "As marcas dos tempos: a interculturalidade nas culturas da infância", Projeto POCTI/ CED/2002, 2002. Disponível em http://titosena.faed. udesc.br/Arquivos/Artigos_infancia/Cultura\%20 na\%20Infancia.pdf. Acesso em: 20 nov. 2019.
SARMENTO, Manuel Jacinto. Visibilidade social e estudo da infância. In: VASCONCELLOS, V. M. R.; SARMENTO, M. J. (Orgs.). Infância (In)visível. Araraquara: Juqueira \& Marin, 2008. p. 25 - 49.

SHYER, Laurence. Robert Wilson and his Collaborators. Nova York: Theatre Communications Group, 1989.

TONEZZI, José. A cena contaminada: um teatro das disfunções. São Paulo: Perspectiva, 2011.

VYGOTSKY, Lev. A formação social da mente. Martins Fontes, 2003.

Recebido: 15/02/2020

Aceito: $15 / 06 / 2020$

Aprovado para publicação: 17/11/2020

Este é um artigo de acesso aberto distribuído sob os termos de uma Licença Crea- tive Commons Atribuição 4.0 Internacional. Disponivel em: <http://creative commons.org/licenses/by/4.0>.

This is an open-access article distributed under the terms of the Creative Commons Attribution License 4.0 International. Available at: <http://creative commons.org/licenses/by/4.0>.

Ce texte en libre accès est placé sous licence Creative Commons Attribution 4.0 International. Disponible sur: <http://creativecommons.org/licenses/by/4.0>. 